\title{
PARA PENSAR SOBRE A FORMAÇÃO CONTINUADA DE PROFESSORES É IMPRESCINDÍVEL UMA TEORIA CRÍTICA DE FORMAÇÃO HUMANA
}

\author{
Clarissa Martins de Araújo * \\ Everson Melquíades Araújo ** \\ Rejane Dias da Silva ***
}

\begin{abstract}
RESUMO: A formação continuada de professores na década de 1990 passou a ser considerada uma das estratégias fundamentais para o processo de construção de um novo perfil profissional do professor. Neste contexto, a concepção crítico-reflexiva foi defendida como a orientação mais adequada para a renovação dos sistemas de formação continuada de professores no Brasil. No entanto, ao longo de duas décadas, diferentes estudos indicam que esta orientação teórico-metodológica operou mudanças pouco significativas nas práticas formativas. A partir de uma revisão sobre a tendência denominada de Epistemologia da Prática, este ensaio propóe um deslocamento da formação continuada de professores do campo das políticas públicas para o campo da formação humana. Nesta direção, procuramos apontar qual a contribuição da teoria crítica da formação humana para os processos de formação continuada de professores na contemporaneidade.
\end{abstract}

Palavras-chave: Formação continuada de professores. Epistemologia da prática. Formação crítica-reflexa. Formação humana.

\footnotetext{
* Universidade Federal de Pernambuco, Centro de Educação, Recife, PE., Brasil. E-mail de contato: cmaraujo@ufpe.br.

** Universidade Federal de Pernambuco, Centro de Educação, Recife, PE., Brasil. E-mail de contato: eversonmelquiades@bol.com.br.

*** Universidade Federal de Pernambuco, Centro de Educação, Recife, PE., Brasil. E-mail de contato: rejanediasilva@hotmail.com.
} 


\section{To think of teachers' continuing education, a critical theory for human capital formation is necessary}

ABSTRACT: Teachers' continuing education in the 1990s came to be considered one of the fundamental strategies for the process of constructing a new professional profile for the teacher. In this context, the critical-reflexive conception was defended as the most adequate orientation to renew systems of continuing education for teachers in Brazil. Nevertheless, through two decades, different studies have indicated that this theoretical-methodological orientation made way for changes of little significance in the practice of capacitating teachers. Setting out from a revision of the tendency denominated Epistemology of Practice, this work proposes a change in the continuing education of teachers, from the field of policies to the field of human capital formation. In this direction, we sought to point out what the contribution of the critical theory of human capital formation would be for contemporary processes of continuing formation in teaching.

Keywords: Teachers' continuing education. Epistemology of practice. Critical-reflexive formation. Human capital formation.

\section{A FORMAÇÃO CONTINUADA DE PROFESSORES COMO POLÍTICA PÚBLICA: UMA BREVE INTRODUÇÃO}

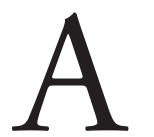

discussão sobre a formação de professores no cenário brasileiro não se constitui em uma temática recente, posto que, desde

a década de 1980, ela se tornou uma das questóes centrais do campo educacional. Tomando de empréstimo uma expressão utilizada por Azevedo (1997), a formação de professores aparece como uma questão socialmente problematizada; uma temática que tem sido tratada no Brasil, até certo ponto, com abundância pela literatura educacional, sob variados ângulos e critérios, e que conta, inclusive, com um amplo movimento de discussão e reflexão institucionalizado sobre o campo denominado "Formação de Professores". 
Dentre esses estudos podemos citar os trabalhos de Krazilchik (1988), Faria Jr. (1989), André (2002), Lima (2003) e Brzezinski $(2006 ; 2007)$. Os autores apontam como objetos de estudo do campo da formação de professores os seguintes campos temáticos: (1) a formação inicial de professores; (2) a formação continuada de professores; (3) a constituição da identidade e a profissionalização docente; (4) as políticas educacionais de formação de professores; (5) história da formação de professores no Brasil, e por fim, (6) os saberes docentes e aprendizagem profissional. No entanto, apesar da amplitude de temáticas deste campo de conhecimento, aqui neste ensaio, iremos discutir especificamente sobre a formação continuada de professores.

Podemos afirmar que a formação continuada de professores no Brasil possui uma trajetória histórica e sócio-epistemológica marcada por diferentes concepçôes, que não se constituíram a priori, mas que vêm emergindo das diversas concepçóes de educação e sociedade presentes na realidade brasileira. No entanto, foi especificamente na década de 1990 que a formação continuada passou a ser considerada uma das estratégias fundamentais para o processo de construção de um novo perfil profissional do professor. (NÓVOA, 1991; ESTRELA, 1997; GATTI, 1997; VEIGA, 1998)

Nesse período tornou-se comum, inclusive, defender que a formação inicial, mesmo em nível superior, embora necessária, não seria uma condição suficiente para garantir o desenvolvimento profissional dos docentes. Assim sendo, a formação permanente dos professores emerge, simultaneamente, como uma necessidade intrínseca dos sistemas de ensino e um direito de todos os professores. Corroborando com essas ideias, Freitas afirma:

A ênfase na formaçáo continuada de professores é fruto, portanto, tanto da pressão e da luta dos profissionais da área e dos movimentos sociais em geral, quanto da racionalidade econômica que reivindicam a eficiência do ensino público, haja vista as mudanças em curso no cenário global. (FREITAS, 2005a, p. 35) 
Não é casual, portanto, que o próprio Ministério da Educação (MEC), através da Secretaria de Ensino Fundamental, tenha instituído nesse período, os chamados "Referenciais para a Formação de Professores" (BRASIL, 1999), com o objetivo explícito de propor e implementar mudanças nas práticas institucionais e curriculares da formação de professores no país. Nessa direção, o referido documento, consagra que:

A formação continuada deve propiciar atualizações, aprofundamento das temáticas educacionais e apóia-se numa reflexão sobre a prática educativa, promovendo um processo constante de auto-avaliaçáo que oriente a construção contínua de competências profissionais. Porém, um processo reflexivo exige predisposição a um questionamento crítico da intervenção educativa e uma análise da prática na perspectiva de seus pressupostos. Isso supóe que a formação continuada estenda-se às capacidades e atitudes e problematize os valores e as concepçôes de cada professor e da equipe. (BRASIL, 1999, p. 70)

A citação acima explicita, de forma clara, que a orientação defendida para a formação continuada dos professores pelos "Referencias para a Formação de Professores" está relacionada à concepção crítico-reflexiva. Portanto, a prática, pautada nesta concepção, foi um conceito central que uniu diferentes autores que propuseram um repensar das políticas de formação de professores na década de 1990 no Brasil. É possível afirmar, desse modo, que no contexto de mudanças em destaque, as reformas educacionais apropriaram-se dessa concepção para estabelecimento de uma política pública de formação de professores, de âmbito nacional, transformando-se em programa de governo.

É importante observar que a formação crítico-reflexiva não é uma concepção de formação criada pelo MEC e seus assessores. $\mathrm{Na}$ realidade, essa concepção vem se constituindo através de um esforço coletivo de intelectuais, pesquisadores e professores que nos últimos anos vêm buscando reinventar, a partir de estudos, pesquisas e práticas institucionais, uma maneira mais pertinente de formar continuamente os professores, já que o modelo convencional, liberal-conservador, estava sendo bastante questionado, principalmente, pela sua ineficácia. 
No entanto, passadas mais de duas décadas, alguns estudos produzidos no âmbito dos programas de pós-graduação em educação do Brasil, indicam que a formação continuada como o processo de reflexão crítica sobre a prática educativa operou mudanças pouco significativas nas práticas formativas. No Programa de Pós-Graduação em Educação da Universidade Federal de Pernambuco (UFPE), por exemplo, vamos encontrar os estudos de Lima (2012), Araújo (2013), Lima (2013), Rocha (2013), Freitas (2014), entre outros. De forma geral, os autores buscaram compreender como as Secretarias de Educação vêm formando continuamente os seus professores e quais as implicaçôes dessa prática formativa para a transformação social da educação escolar. Essas diferentes pesquisas nos indicam que as Secretarias de Educação se pautam, em grande medida, em uma concepção liberal-conservadora, também denominada de racionalidade técnica, apontando para a necessidade de mudanças dos modelos de formação continuada de seus professores propostos pelo Estado e Município.

Para uma melhor compreensão do fenômeno apresentado pelas pesquisas desenvolvidas nos programas de pós-graduação, apresentaremos na próxima sessão, uma breve caracterização da formação continuada de professores dentro da perspectiva da epistemologia da prática e exemplos de análises críticas imputadas sobre esta compreensão teórico-metodológica.

\section{A FORMAÇÃO CONTINUADA DE PROFESSORES: UM OLHAR A PARTIR DA EPISTEMOLOGIA DA PRÁTICA}

A formação de professores dentro de uma perspectiva da "epistemologia da prática", ou "racionalidade prática", está baseada em grande medida na teoria dos saberes docentes de Tardif (2002) e da teoria do professor prático reflexivo em Zeichner (1993; 1995). Esta tendência compreende o professor como um intelectual capaz de produzir conhecimentos e teorias a partir da reflexão sobre a sua prática.

Como orientação fundamental para a formação continuada de professores, a epistemologia da prática deve incentivar a apropriação dos saberes pelos professores rumo à autonomia e levar a uma prática crítico- 
-reflexiva, abrangendo a vida cotidiana da escola e os saberes derivados da experiência docente. Isso significa que o professor precisa refletir sobre sua prática em suas múltiplas dimensões. (ARAÚJO; SILVA, 2009)

Dessa maneira, o espaço de formação do professor será a escola e o conteúdo dessa formação a sua prática educativa. O professor reflexivo será "[...] um investigador da sala de aula, que formula suas estratégias e reconstrói a sua ação pedagógica [...]” (ALMEIDA, 2002, p. 28), pois, como afirma Silva (2002, p. 28), "[...] a prática transforma-se em fonte de investigação, de experimentação e de indicação de conteúdo para a formação [...]". Enfim, a postura reflexiva não requer apenas do professor o saber fazer, mas que ele possa saber explicar, de forma consciente, a sua prática e as decisóes tomadas sobre ela e perceber se essas decisóes são as melhores para favorecer a aprendizagem do seu aluno.

No entanto, esta orientação teórico-metodológica já vem sendo alvo de uma série de críticas, uma vez que ao ser apropriado pelas agendas governamentais, provocou alguns equívocos e contradiçôes, estabelecendo, inclusive, uma visão reducionista sobre os processos da formação docente, conforme, apresentaremos a seguir, a partir de algumas consideraçóes críticas sobre os estudos de Tardif (2002) e Zeichner (1993; 1995).

É fato que a reflexão sobre a prática vem se constituindo no Brasil desde o final da década de 1990, conforme apontamos anteriormente, como um dos elementos centrais no processo de reconfiguração das práticas de formação de professores e como um mecanismo de transformação da prática de ensino. No entanto, não podemos deixar de chamar atenção a outros elementos que contribuem para a formação de professores, tais como nos sinaliza Alves (1995) apud Carvalho e Simóes (1999, p. 4), a saber:

[...] (1) a socialização do conhecimento produzido pela humanidade; (2) as diferentes áreas de atuaçáo; (3) a relação ação-reflexão-ação; (4) o envolvimento do professor em planos sistemáticos de estudo individual ou coletivo; (5) as necessidades concretas da escola e dos seus profissionais; (6) a valorização da experiência do profissional. Mas, também: (7) a continuidade e a amplitude das açóes empreendidas; (8) a explicitação 
das diferentes políticas para a educação pública; (9) o compromisso com a mudança; (10) o trabalho coletivo; (11) a associação com a pesquisa científica desenvolvida em diferentes campos do saber.

Apesar da presença de teóricos como Schön (1995, 2000), Gomes (1995), Alarcão (2001, 2003) e Pimenta (2002), a ideia de professor reflexivo foi amplamente divulgada no Brasil a partir dos diferentes estudos de Zeichner (1993; 1995).

No que se refere a avaliação crítica do impacto da ideia de professor reflexivo no cenário educacional, é possível afirmar que a teoria da reflexão sobre a prática operou poucas transformações na realidade educativa, isto porque a reflexão foi reduzida a prática de ensino, mais especificamente, aos processos de ensinar e aprender na sala de aula. Entendemos que esta reflexão deve ser ampliada para as esferas sociais, políticas, históricas e econômicas onde está inserida a prática docente, para que não reproduzamos os sistemas que vêm se instituindo historicamente, em uma sociedade marcada por tempos de incerteza e desigualdades sociais crescentes, isto porque a prática educativa não é descolada das outras práticas existentes no mundo, na vida real. A essa reflexão mais ampla sobre a realidade, é preciso acrescentar também a necessidade de uma reflexão crítica sobre si mesmo e sobre a sua relação com o mundo. Nesta perspectiva, Zeichner (PEREIRA-DINIZ, 2008) indica a justiça social como um mecanismo possível para um repensar crítico do processo de formação de professores.

Já no processo de reconhecimento do professor como um sujeito produtor de saberes, Tardif (2002) representa uma das contribuiçôes mais significadas no cenário acadêmico brasileiro. No entanto, seus estudos apresentam uma compreensão limitada sobre a noção de experiência, que a restringe às vivências como aluno, nas relaçôes familiares, dentre outros, das quais derivam os saberes experienciais no conjunto dos saberes docentes. ${ }^{1}$ Neste sentido, não é suficiente proclamar a existência de saberes derivados da experiência, é preciso ter clareza daquilo que estamos denominando de experiência, conforme nos alerta Dewey (1976, p. 17): "Quanto mais definitiva e sinceramente se sustenta que educação é desenvolvimento dentro, por e para a experiência, tanto mais 
importante se faz a necessidade de clara concepção do que seja experiência $[\ldots] "$.

A partir desta breve revisão sobre a tendência denominada de Epistemologia da Prática, nos propomos apontar, na próxima sessão, qual a contribuição de uma teoria crítica da formação humana para os processos de formação continuada de professores na contemporaneidade.

\section{FORMAÇÃO CONTINUADA DE PROFESSORES: POR UM PROCESSO DE FORMAÇÃO DO SUJEITO HUMANO}

Para a compreensão do deslocamento da formação continuada de professores do campo das políticas públicas para o campo da formação humana, faz-se necessário diferenciarmos o processo de formação de outros processos, que comumente no campo da educação, são evocados como sinônimos, tais como Ensino, Instrução e Treinamento, conforme nos sugerem os estudos de Freitas (2005b).

Segundo o referido autor, o termo Ensinar tem sua origem no latim, insignare, que significa conferir marca, uma distinção. Aproxima-se dos vocábulos aprender, explicar, demonstrar e, desta forma, confere um sentido predominantemente operatório, metodológico e institucional. $\mathrm{O}$ ensino é uma educação formal, que se exerce numa instituição; seus métodos são decodificados e esta é assegurada por profissionais da educaçáo. Instruir, também originado do vocábulo latino instruere, significa inserir. Desta forma, a instrução apela aos conteúdos a serem transmitidos, fornecendo, ao espírito humano, instrumentos intelectuais. Já o termo treinar indica um aspecto de instrumentalização, no sentido de canalizar todas as energias disponíveis, sejam elas físicas, intelectuais ou morais, para atingir determinados fins úteis. Poderíamos dizer que o treinamento reclama da educação o exercício de suas dimensôes pragmáticas. Por fim, formar, do latim, formare, significa dar ao ser a forma. $\mathrm{O}$ vocabulário apela a uma acepção profunda e global da pessoa; transformação de todo ser, reconfigurando seus saberes: saber saber, saber fazer e saber ser. Nesta perspectiva, formar tem uma dimensão ontológica, já que, na formação, é o próprio ser que está em causa na sua forma. Ela apela para uma enunciação, pelo próprio sujeito, de questôes que representam 
como "seu projeto", de seu devir consigo próprio e com os outros, o que poderíamos chamar de cuidado de si. Neste sentido, privilegia a autorreflexão no sentido de uma desestruturação-reestruturação contínua das identidades enquanto "ser multidimensional".

Assim sendo, é possível afirmar que a formação continuada de professores, tanto na perspectiva da Racionalidade Técnica como na Racionalidade Prática, aproxima-se, em sua essência, dos vocábulos ensino, instrução e treinamento, uma vez que estas compreensões tem como prerrogativa a aprendizagem de conhecimentos, onde na primeira esse processo é estabelecido através da aquisição de informaçôes científicas, didáticas e psicopedagógicas descontextualizadas da prática educativa do professor, e na segunda, consiste em construir conhecimentos e teorias sobre a prática docente, a partir da reflexão crítica, também com base em informaçôes científicas, didáticas e psicopedagógicas, contudo, estas de forma contextualizadas. No entanto, destacamos que ambas não consideram os elementos da existência humana dos professores em formação.

Diferente dessas concepçóes, a formação continuada de professores na perspectiva da formação humana, aproxima-se do vocábulo formação, uma vez que se constitui de um processo existencial. Como nos afirma Freitas (1997, p. 7-8), "O quanto de memória, isto é, de história e de desejo, existe na escolha de uma vida?". Assim, "Somos, portanto, História: Arma e armadura. Deslocamo-nos entre o dado e o criado, entre o passado, o presente e o futuro; reconstruindo, refazendo, tecendo de modo artesanal a Vida”. Em sentido radical, é um processo de reinvenção de si mesmo e de intervenção no mundo, ou seja, é um processo de problematização e subjetivação da realidade.

É neste bojo que emerge a compreensão da formação continuada de professores como um ato pedagógico, como a metáfora da responsabilidade de se falar do primeiro dia, como nos alerta Freitas (1997, p. 6):

Daí a responsabilidade de se querer falar do primeiro Dia: a responsabilidade por nosso desejo; a responsabilidade de dizer a "verdade" desse desejo do qual não podemos ter nenhum conhecimento, mas que está "escrito" no enigma de nossos destinos, é um tipo de 
responsabilidade profundamente educativa, na medida em que uma das dimensóes do ato pedagógico, é o movimento que nos faz ir do saber do desejo ao desejo do saber.

Complementa ainda o autor:

No primeiro Dia era o Verbo, e o Verbo se fez carne! Por que? Por que não nascemos da carne, nem do sangue, mas do Desejo, da Palavra. Nascemos de uma alquimia verbal. A palavra é, portanto, construtora de mundos, mundos habitados pelo Desejo! Infelizmente, o discurso cientificista tornou o Homem incapaz de reconhecer seus próprios desejos, que se perderam num esquecimento imposto. (FREITAS, 1997, p. 6)

Diante do exposto, o deslocamento da formação continuada de professores do campo das políticas públicas para o campo da formação humana procura compreender o processo de formaçáo continuada de professores como um processo de formação do sujeito humano, em seu sentido radical, aproximando as práticas de formação do professor aos princípios da educação como Bildung.

Sobre a formação como Bildung, Freitas (2005b) fez uma interessante reconstituição da trajetória desta noção, na tradição do pensamento filosófico alemão, baseado em significativos estudos, tais como os de Bolle (1997) e Freitag (1994). Em síntese, o autor indica que "A Bildung é apreendida como o 'princípio pedagógico', por excelência, da formação de si pelo cultivo de 'bens seculares' (liberdade, autonomia, responsabilidade) [...]”. (FREITAS, 2005b, p. 123) Desta forma, a formação como Bildung constitui-se de um processo de autoformação e autodesenvolvimento dos aspectos físicos, psíquicos, morais e intelectuais do ser humano. 
Compartilhando da noção de Bildung, utilizamos neste ensaio a compreensão de formação humana como um processo no qual o homem, percebendo-se como um ser inacabado procura desenvolver-se em todos os sentidos, aperfeiçoando-se cada vez mais para relacionar-se com a realidade que o cerca. Ele mesmo é corresponsável por sua formação, e, portanto, por proporcionar a si mesmo experiências nas quais possa se aproximar cada vez mais da sua humanidade. (RÖHR, 2002; 2006)

Esta compreensão nos faz entender claramente que nem toda formação continuada constitui-se, a priori, em um processo de formação humana. Mas, dependendo de como este processo será conduzido e assumido pelos sujeitos em formação, as experiências educativas possibilitadas por esses processos poderão converter-se em aspectos positivos para a formação humana dos sujeitos.

No entanto, não é possível abrir mão da crença de que é preciso defender que todo processo educativo deveria possibilitar o crescimento integral do ser humano, nas suas diferentes áreas, sejam elas afetivas, cognitivas, físicas ou morais, baseados nos princípios da solidariedade, da democracia, da justiça social e humanidade nas relaçóes sociais, revertendo-se em um processo de espiritualização. (RÖHR, 2010) Se qualquer prática educativa não possibilitar a humanização dos sujeitos, elas não possuem valor educativo. Logo, se a formação continuada não criar condiçóes para a humanização e crescimento integral dos professores, essa não se constitui em prática de formação humana.

É preciso ficar claro que o sentido da formação humana não é instituído nas práticas de formação de professores pelas políticas públicas do campo da educação, posto que os processos humanos extrapolam as objetividades de qualquer programa de formação de professores. Só os formadores de professores e os próprios professores poderão dar esse sentido à formação de professores, inserindo esses processos de formação como um projeto de existencialidade na sua vida.

$\mathrm{Na}$ próxima seção, apresentaremos as consideraçôes finais do nosso trabalho e suas contribuiçóes para um repensar crítico do campo da formação continuada de professores. 


\section{POR UMA TEORIA CRÍTICA DE FORMAÇÃO HUMANA: A TÍTULO DE CONSIDERAÇÕES}

Sabemos que o deslocamento do campo da formação de professores das políticas públicas para o campo da formação humana constitui-se, dentro de uma sociedade capitalista em tempos de desigualdades crescentes, um projeto formativo de ideal utópico. Em sentido freireano, a utopia é a esperança crítica de transformação da realidade. (FREIRE, 1992) Para o autor (1979, p. 27), “[...] o utópico não é o irrealizável; a utopia não é idealista, é a dialetização dos atos de denunciar e anunciar, o ato de denunciar a estrutura desumanizante e de anunciar a estrutura humanizante [...]”. Sem o mínimo de esperança não é possível o início da luta. Desta forma, a utopia crítica se faz necessária para que o processo educativo se estabeleça como um enfrentamento à realidade atual, como nos alerta Freitas (2008, p. 418):

A utopia freireana está relacionada à concretização dos sonhos possíveis e decorre de sua compreensão da história como possibilidade, ou seja, a compreensão acerca de que a realidade não 'é', mas 'está sendo' e que, portanto, pode vir a ser transformada [...].

Nesta perspectiva, é possível acreditarmos, desejarmos, sonharmos e defendermos a formação continuada de professores dentro de uma perspectiva da formação humana.

Desse modo, o professor forma a si próprio através da compreensão crítica de seu processo de formação como sujeito humano. (JOSSO, 2004) Para este autor todo processo de formação é autoformação, todo processo de conhecimento é autoconhecimento, perspectiva que também se aproxima da noção de formação como Bildung. (BOLLE, 1997) Segundo Freitas (2005a, p. 41), “[...] do ponto de vista de uma 'teoria da formação', a produção dos objetos de saber e dos conhecimentos mantém um vínculo estreito com as histórias de vida pessoal e profissional dos educadores [...]". Isso nos indica que é preciso buscar nos fundamentos da Educação, elementos para uma teoria da formação humana. Assim sendo, acreditamos ser preciso assumir de forma refle- 
xiva uma filosofia da educação que guie as nossas práticas de formação continuada de professores, pois para um pensar crítico e transformador sobre a formação de professores é imprescindível uma teoria crítica sobre a formação humana, como é proposto por Freitas (2005a), Silva (2010) e Röhr (2010).

\section{REFERÊNCIAS}

ALARCÃO, I. Professores Reflexivos em uma Escola Reflexiva. São Paulo: Cortez, 2003.

. Escola Reflexiva e Nova Racionalidade. Porto Alegre: ArtMed, 2001.

ALMEIDA, E. R. de S. A formação dos professores das classes especiais para o uso do computador na sala de aula. 2002. Projeto de dissertação (Mestrado em Educação) - Universidade Federal de Pernambuco. Recife, 2002.

ANDRÉ, M. (Org.). Formação de professores no Brasil (1990-1998). Brasília: MEC/Inep/Comped, 2002.

ARAÚJO, F. R. dos S. Formaçâo continuada da rede municipal de ensino do Jaboatão dos Guararapes: caminhos e descaminhos de uma prática docente humanizadora. 2013. Dissertação. (Mestrado em Educaçáo). Programa de Pós-Graduação em Educação. Centro de Educação. Universidade Federal de Pernambuco. Recife, 2013.

ARAÚJO, C. M.; SILVA, E. M. Formaçấo continuada de professores: tendências emergentes na década de 1990. Educação, Porto Alegre, v. 32, n. 3, p. 326-330, set./dez. 2009.

AZEVEDO, J. M. L. de. A Educação como Política Pública. São Paulo: Cortez, 1997.

BENJAMIN, W. Magia e técnica, arte e política. São Paulo: Brasiliense, 1994. . Reflexóes sobre a criança, o brinquedo e a educação. São Paulo: Duas Cidades; Editora 34, 2002.

BOLLE, W. A Idéia de Formação na Modernidade. In: GUIRALDELLI JR, P. (Org.). Infância, Escola e Modernidade. São Paulo: Cortez; Curitiba: Editora UFPR, 1997. 
BRASIL. MINISTÉRIO DA EDUCAÇÃO. SECRETARIA DE EDUCAÇÃO FUNDAMENTAL. Referenciais para a Formação de Professores. Brasília: $\mathrm{SEF} / \mathrm{MEC}, 1999$.

BRZEZINSKI, I. (Org.). Formação de profissionais da educação (1997-2002). Brasília: MEC/Inep/Comped, 2006.

BRZEZINSKI, I. GT 8: A pesquisa sobre formação de profissionais da educação em 25 anos de história. In: REUNIÃO ANUAL DA ASSOCIAÇÃO NACIONAL DE PÓS-GRADUAÇÃO E PESQUISA EM EDUCAÇÃO, 30., 2008, Caxambú. Anais... Caxambú: ANPED, 2007.

CARVALHO, J. M.; SIMÓES, R. H. S. O que dizem os artigos publicados em periódicos especializados, na década de 90 sobre o processo de formação continuada de professora? In: REUNIÃO ANUAL DA ASSOCIAÇÃO NACIONAL DE PÓS-GRADUAÇÃO E PESQUISA EM EDUCAÇÃO, 22. 1999, Caxambu. Anais... Caxambú: ANPED, 1999.

DEWEY, J. Democracia e Educação: capítulos essenciais. São Paulo: Ática, 2007. 1976.

. Experiência e Educação. São Paulo: Companhia Editora Nacional, . El hombre e sus problemas. Buenos Aires: Editorial Paidos, 1961.

- Como Pensamos: como se relaciona o pensamento reflexivo com o processo educativo: uma reexposição. São Paulo: Companhia Editora Nacional, 1959.

ESTRELA, M. T. Viver e construir a profissão docente. Portugal: Porto Editora, 1997.

FARIA JR., A. Relatório do GT Licenciaturas. Boletim ANPED, São Paulo, v. 10, n. 1-2, p. 78-79, jan./jun. 1989.

FREIRE, P. Pedagogia da Esperança: um encontro com a Pedagogia do Oprimido. Rio de Janeiro: Paz e Terra, 1992.

. Educação e Mudança. Rio de Janeiro: Paz e Terra, 1979.

FREITAG, B. O Indivíduo em Formação. São Paulo: Cortez, 1994.

FREITAS, A. S. de. Utopia. In: STRECK, D. R.; RENDIN, E.; ZITKOSKI, J. J. (Orgs.). Dicionário Paulo Freire. Belo Horizonte: Autêntica, 2008.

. A questão da experiência na formação profissional dos professores. In: FERREIRA, A. T. B.; ALBUQUERQUE, E. B. C.; LEAL, T. F. Formação continuada de professores: questóes para reflexão. Belo Horizonte: Autêntica, 2005a. 
FREITAS, A. S. de. Fundamentos para uma sociologia critica da formação bumana: um estudo sobre o papel das redes associacionistas. 2005. 396f. Tese (Doutorado em Sociologia). Programa de Pós-Graduação em Sociologia. Centro de Ciências Humanas e Filosofia. Universidade Federal de Pernambuco. Recife, $2005 b$.

. Mas, o que é mesmo essa coisa chamada amor. In: MELQUIADES, E.; SANTOS, S. O primeiro dia. Olinda: Mímeo, 1997.

FREITAS, M. B. O brincar e a ludicidade como saberes da profissionalidade docente na educação infantil: contributos e paradoxos da formação continuada na escola. 2014. Tese. (Doutorado em Educação). Programa de Pós-Graduação em Educação. Centro de Educação. Universidade Federal de Pernambuco. Recife, 2014.

GATTI, B. Formação de professores e carreira: problemas e movimentos de renovação. Campinas: Autores Associados, 1997.

GÓMEZ, A. P. Formar Professores como Profissionais Reflexivos. In: NÓVOA, A. (Coord.). Os Professores e a sua Formação. Lisboa: Publicaçóes Dom Quixote; Instituto de Inovação Educacional, 1995.

JOSSO, M-C. Experiências de Vida e Formação. São Paulo: Cortez, 2004.

KRAZILCHIK, M. Relatório do GT Licenciaturas. Boletim ANPED, Porto Alegre, v. 10, n. 2-3, p. 29-30, abr./set. 1988.

LIMA, E. F. et al. Análise crítica dos trabalhos apresentados no GT 8 no período 1999-2003. In: REUNIÃO ANUAL DA ASSOCIAÇÃO NACIONAL DE PÓS-GRADUAÇÃO E PESQUISA EM EDUCAÇÃO, 26., 2003, Caxambu. Anais... Caxambú: Anped, 2003.

LIMA, D. R. de. Contributos da formaçáo continuada no processo de reconfiguração da profissionalidade docente: desenvolvimento da prática reflexiva em questão. 2013. Dissertação. (Mestrado em Educação). Programa de Pós-Graduação em Educação. Centro de Educação. Universidade Federal de Pernambuco. Recife, 2013.

LIMA, R. da C. A formação continuada nas representaçóes sociais de seus formadores. 2012. Dissertação. (Mestrado em Educação). Programa de Pós-Graduação em Educação. Centro de Educação. Universidade Federal de Pernambuco. Recife, 2012.

NÓVOA, A. Formação contínua de professores: realidades e perspectivas. Aveiro: Universidade de Aveio, 1991. 
PEREIRA-DINIZ, J. E.; ZEICHER, K. M. (Orgs.). Justiça Social: desafio para a Formação de Professores. Belo Horizonte: Autêntica, 2008.

PIMENTA, S. G.; GHEDIN, E. (Orgs.). Professor reflexivo no Brasil: gênese e crítica de um conceito. São Paulo: Cortez, 2002.

ROCHA, A. A constituição de proposta de formação continuada de professores da rede municipal de ensino para o atendimento a diversidade do alunado: concepçóes, limites e possibilidades. 2013. Dissertação. (Mestrado em Educação). Programa de Pós-Graduação em Educação. Centro de Educação. Universidade Federal de Pernambuco. Recife, 2013.

RÖHR, F. (Org.). Diálogos em Educaçâo e Espiritualidade. Recife: Ed. Universitária da UFPE, 2010.

. Reflexóes em torno de um possível objeto epistêmico próprio da Educação. Pro-Posiçôes, v. 18, n. 1 (52), jan./abr. 2006.

. Ética Pedagógica na Educação Espiritual - Um estudo comparativo. In: ENCONTRO DE FILOSOFIA DA EDUCAÇÁO DO NORTE E NORDESTE, 2002, Recife. Anais ... Recife: Editora Universitária da UFPE, 2002. v. 1. p. 1-28.

. Educando o Profissional Reflexivo: um novo design para o ensino e a aprendizagem. Porto Alegre: Artmed, 2000.

. Formar professores como profissionais reflexivos. In: NÓVOA, A. (Org.). Os professores e sua formação. Lisboa: Publicaçôes Dom Quixote; Instituto de Inovação Pedagógica, 1995.

SILVA, E. M. A. A formação do arteleducador: um estudo sobre história de vida, experiência e identidade. 2010. 287f. Tese. (Doutorado em Educação). Programa de Pós-Graduação em Educação. Centro de Educação. Universidade Federal de Pernambuco. Recife, 2010.

SILVA, J. B. da. As representaçôes sociais dos professores em classes multisseriadas sobre a formação continuada. 2002. 136f. Dissertação (Mestrado em Educação). Programa de Pós-Graduação em Educação. Centro de Educação. Universidade Federal de Pernambuco. Recife, 2002.

TARDIF, M. Saberes docentes e formaçâo profissional. Petrópolis: Vozes, 2002.

VEIGA, I. P. Caminhos da profissionalização do magistério. Campinas: Papirus, 1998 . 
ZEICHNER, K M. Novos Caminhos para o practicum: uma perspectiva para os anos 90. In: NÓVOA, A. (Org.). Os Professores e sua Formação. Lisboa: Publicações Dom Quixote; Instituto de Inovação Pedagógica, 1995.

. A Formação Reflexiva de Professores: idéias e práticas. Lisboa: EDUCA, 1993.

\section{NOTAS}

1. Para maior compreensão do conceito de vivência e experiência ler as obras de Benjamim (1994; 2002) e John Dewey (1959; 1961; 1976; 2007).

Recebido em 06 de março de 2015.

Aprovado em 11 de maio de 2015.

DOI: http://dx.doi.org/10.1590/CC0101-32622015146820 